\title{
MULTIPLE NON-OSSIFYING FIBROMATA WITH EXTRASKELETAL ANOMALIES: A NEW SYNDROME?
}

\author{
M. CAMPANACCI, M. LAUS, S. BORIANI \\ From the Istituto Ortopedico Rizzoli, Bologna
}

\begin{abstract}
Ten patients with multiple non-ossifying fibromata are reported. All had associated extraskeletal congenital anomalies such as café-au-lait spots, mental retardation, hypogonadism or cryptorchidism, ocular anomalies or cardiovascular malformations.

The radiographic picture and the distribution of the skeletal lesions are characteristic and constant. There are lucent areas in the shaft with a sclerotic margin; these areas narrow the medullary canal or may completely fill it. It is suggested that these features characterise a new malformation syndrome, possibly allied to neurofibromatosis. After skeletal maturation is complete, the skeletal lesions may (like non-ossifying fibromata) regress and undergo spontaneous healing.
\end{abstract}

Fibrous tumours in bone occur in two radiographically distinct forms: the smaller variety is usually called a fibrous cortical defect, and the larger a non-ossifying fibroma. An extensive radiographic investigation of the skeleton in children aged between four and 10 years frequently reveals multiple fibrous cortical defects (Caffey 1955). Rarely, however, have multiple non-ossifying fibromata been described. Jaffe (1958) mentions the possibility of multiple non-ossifying fibromata in association with café-au-lait spots, distinguishing the combination from fibrous dysplasia and neurofibromatosis. Evans and Park (1978) reported three patients in the same family all with multiple non-ossifying fibromata. Other single case reports have been published by Pitcock (1971), The Netherlands Committee on Bone Tumours (1973), Dahlin (1978) and Mirra, Gold and Rand (1982).

The association of multiple non-ossifying fibromata with extraskeletal congenital anomalies has not previously been described. In this article we present the clinical and radiographic evidence of a peculiar syndrome showing this association in 10 patients.

\section{MATERIAL}

We isolated 10 cases of multiple lesions amongst 96 cases of histologically proved non-ossifying fibromata. The majority of these patients were operated on elsewhere and sent to us for consultation; the operation had usually been an excision biopsy which, in our judgement, had in most cases been unnecessary. Five of these 10 cases were originally diagnosed as polyostotic fibrous dysplasia.

M. Campanacci, MD, Professor of Orthopaedics, University of Bologna M. Laus, MD, Attending Surgeon

S. Boriani, MD, Attending Surgeon

Istituto Ortopedico Rizzoli, Via Codivilla 9, 40136 Bologna, Italy.

Requests for reprints should be sent to Professor M. Campanacci.

(C) 1983 British Editorial Society of Bone and Joint Surgery $0301-620 \mathrm{X} / 83 / 5125 \$ 2.00$
Each patient had at least three non-ossifying fibromata, as shown in an extensive radiographic survey of the skeleton (Fig. 1), but a biopsy was done of only one lesion in each patient, showing the typical features of non-ossifying fibromata. Altogether there were 67 lesions.

The follow-up ranged from 2 to 20 years.

\section{FINDINGS}

Clinical findings. The age at diagnosis ranged from 5 to 18 years. There were seven boys and three girls. The distribution of the lesions is shown in Figure 1; it tended to be exclusively or predominantly unilateral. No patient had a family history of the disease. The main clinical data are summarised in Table $I$.

Six patients had numerous café-au-lait spots of the "coast of Maine" type; in four they were scattered over

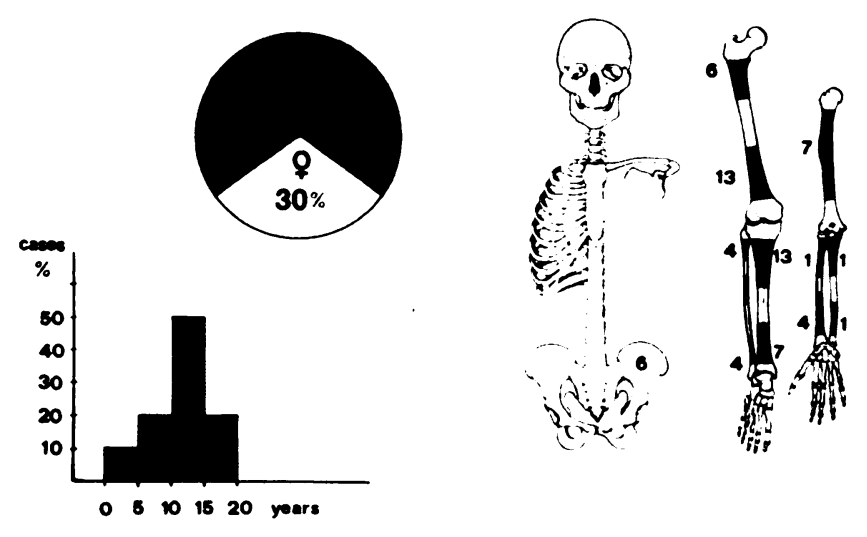

Fig. 1

Age, sex and site of 67 skeletal lesions in 10 patients with multiple nonossifying fibromata. 
Table I. Clinical details of 10 patients with multiple non-ossifying fibromata

\begin{tabular}{|c|c|c|c|c|c|c|c|c|c|}
\hline Case & Sex & $\begin{array}{l}\text { Age } \\
\text { (years) }\end{array}$ & $\begin{array}{l}\text { Distribution } \\
\text { of fibromata }\end{array}$ & $\begin{array}{l}\text { Café-au-lait } \\
\text { spots }\end{array}$ & $\begin{array}{l}\text { Mental } \\
\text { retarda- } \\
\text { tion }\end{array}$ & $\begin{array}{l}\text { Hypogonadism } \\
\text { and/or } \\
\text { cryptorchidism }\end{array}$ & $\begin{array}{l}\text { Ocular } \\
\text { anomalies }\end{array}$ & $\begin{array}{l}\text { Cardio- } \\
\text { vascular } \\
\text { anomalies }\end{array}$ & Remarks \\
\hline 1 & $\mathbf{M}$ & 11 & $\begin{array}{l}\text { Mainly right } \\
\text { sided }\end{array}$ & + & + & $+1+$ & - & + & $\begin{array}{l}\text { Four pathological fractures; } \\
\text { tibial osteotomy for valgus } \\
\text { deformity of the knee }\end{array}$ \\
\hline 2 & $\mathrm{~F}$ & 6 & Right sided & - & + & - & - & - & $\begin{array}{l}\text { One pathological fracture; } \\
\text { tibial osteotomy for varus } \\
\text { deformity of the knee }\end{array}$ \\
\hline 3 & $\mathbf{M}$ & 17 & Lower limbs & + & + & $+1+$ & - & + & - \\
\hline 4 & $\mathbf{M}$ & 12 & Right sided & - & + & + & + & - & $\begin{array}{l}\text { Two pathological fractures; } \\
\text { kyphoscoliosis, epiphysiolysis }\end{array}$ \\
\hline 5 & $\mathbf{M}$ & 11 & Diffuse & $\begin{array}{l}+ \text { (right } \\
\text { sided) }\end{array}$ & + & - & + & - & $\begin{array}{l}\text { Precocious puberty, alopecia, } \\
\text { two pathological fractures; } \\
\text { tibial osteotomy for valgus } \\
\text { deformity of the knee }\end{array}$ \\
\hline 6 & $\mathrm{~F}$ & 5 & Left upper limb & - & - & - & - & + & One pathological fracture \\
\hline 7 & $\mathbf{F}$ & 18 & Left sided & - & - & + & - & - & - \\
\hline 8 & $\mathbf{M}$ & 12 & Lower limbs & + & + & - & - & - & - \\
\hline 9 & $\mathbf{M}$ & 14 & Diffuse & $\begin{array}{l}+ \text { (right } \\
\text { sided) }\end{array}$ & - & $+/+$ & + & - & $\begin{array}{l}\text { One pathological fracture; } \\
\text { mega-ureter }\end{array}$ \\
\hline 10 & $\mathbf{M}$ & 6 & $\begin{array}{l}\text { Right lower } \\
\text { limb }\end{array}$ & + & - & $+1+$ & - & - & $\begin{array}{l}\text { One pathological fracture; } \\
\text { valgus deformity of the knee }\end{array}$ \\
\hline
\end{tabular}

the entire body, but in two patients they were limited to one side of the body (see Figs 9 and 10). Six patients were mentally retarded. Six patients (one girl and five boys) had hypogonadism. In four of the seven boys there was cryptorchidism, unilateral in two and bilateral in two: three of them had a deficiency of pituitary gonadotrophins.

Congenital anomalies of the eye were noticed in three patients. One had a unilateral cataract associated with ectropion; the second had a bilateral complex malformation comprising conjunctival dermolipoma, colobomata of the papilla, and pigmentary dispersion of the retina; the third had a malformation of an eyelid.

Three patients had cardiovascular anomalies : mitral insufficiency which was probably congenital in two, and stenosis of the aortic isthmus in one.

There were single cases of precocious puberty, alopecia (Fig. 10), kyphoscoliosis with epiphysiolysis, and mega-ureter.

Seven of the patients each experienced one or more fractures, always occurring before puberty and always healing with routine treatment. Four patients were left with knee deformities, three in valgus and one in varus. In three of these patients corrective tibial osteotomy was performed and healed in the normal time.

Radiographic picture. The radiographic picture is fairly typical. The osteolytic lesions are initially in the cortex (Fig. 13) but sometimes they expand to occupy the entire cross-section of a tubular bone, which then has a loculated appearance (Figs 2, 3 and 4). Peripherally the lesion is circumscribed by a very thin shell of bone, or by the periosteum alone. In the latter case it may appear as a subperiosteal excavation (Figs 6, 16, 17, 20, 21, 22, 23). On its medullary side the lesion has a well-defined sclerotic border, which encroaches on the medullary canal (Fig. 13).

The location is usually metaphysial (Figs 16, 17, 20, $21,22,23)$, but may extend, sometimes extensively, into the diaphysis (Figs 2, 3, 4, 7, 8, 11, 12). When the nonossifying fibromata are bilateral, the radiographic features tend to be fairly symmetrical in both limbs (Figs $11,12,16,17,22,23)$. The frequent involvement of the diaphyses and pelvis (Fig. 5) is not a feature of the ordinary single non-ossifying fibroma. In the humerus the lesions extend from the proximal metaphysis to the distal third of the diaphysis (Figs 2, 7, 11, 12,13). In only one lesion in the proximal ulna was the epiphysis involved (Figs 2, 3, 4).

Natural history. The natural history of multiple nonossifying fibroma is similar to that of the familiar solitary lesion. With the completion of skeletal growth the osteolytic areas stop enlarging; then they tend to heal spontaneously through an increase of the sclerotic bone at the periphery combined with ossification in the interior of the lesion. This repair may be incomplete (Figs 14, 15, $18,19)$ or complete (Figs 24,25 ). In our patients, no instance of pathological fracture occurred after the age of 15 . 


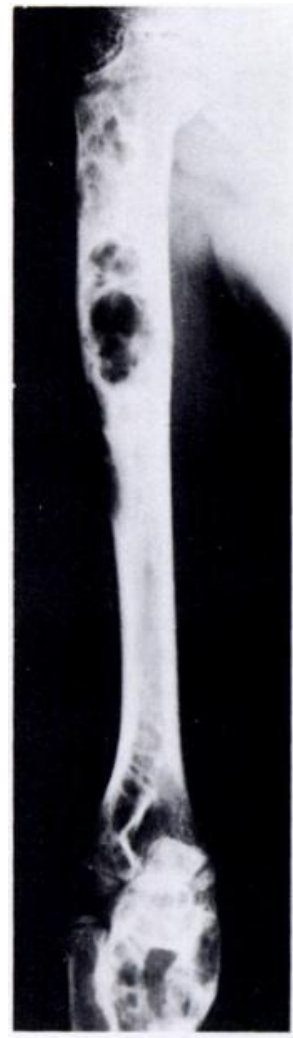

Fig. 2

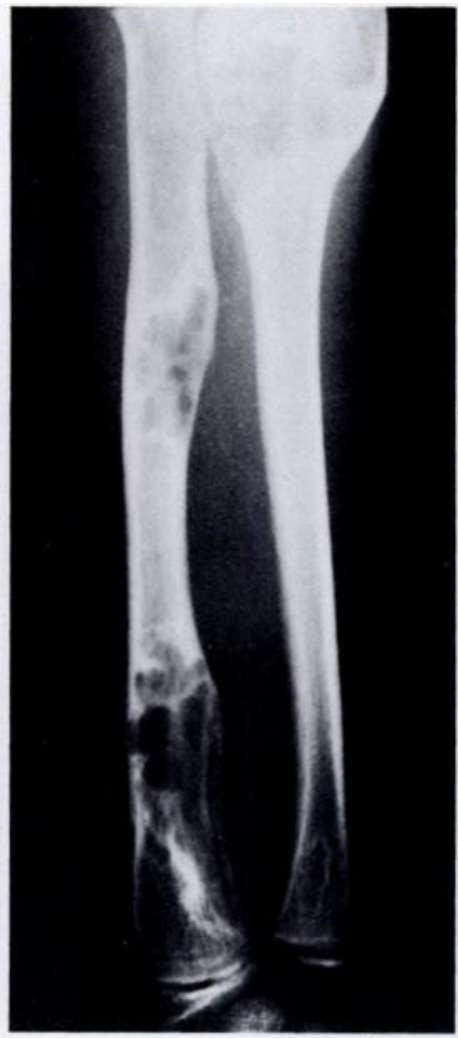

Fig. 3

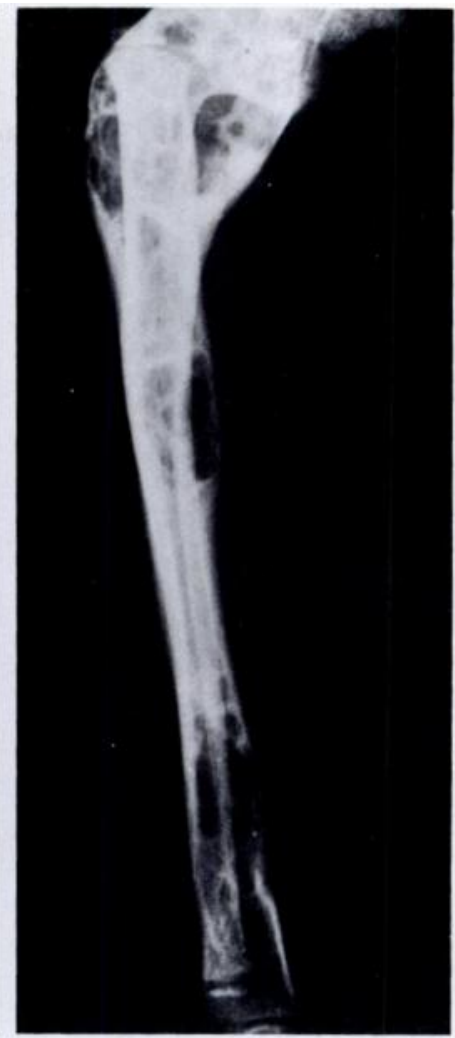

Fig. 4

Case 1. An 11-year-old boy with multiple non-ossifying fibromata mainly affecting the right side of the body. Figure 2 -Typical lesion involving the right humerus. Figures 3 and $4-$ Non-ossifying fibromata of the proximal and distal radius and the proximal ulna. The lesion in the ulna also involves the upper epiphysis.

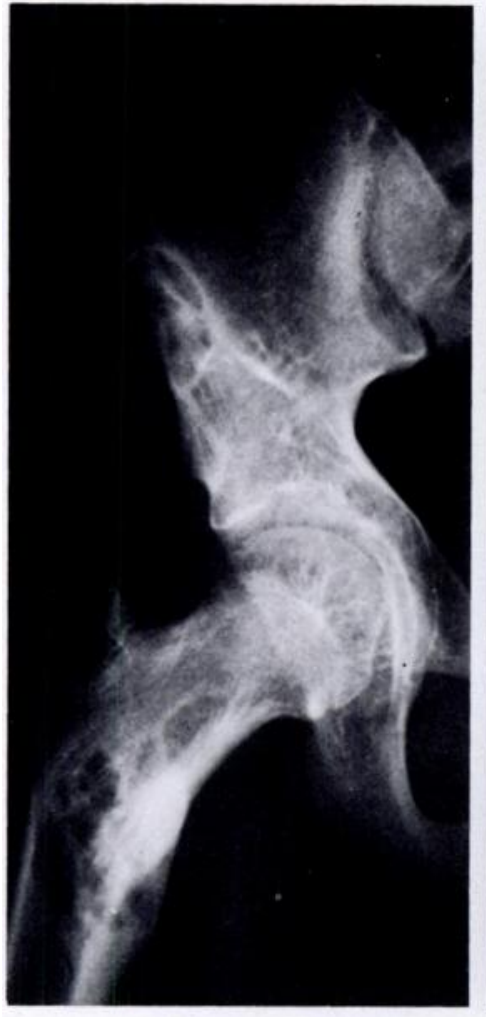

Fig. 5

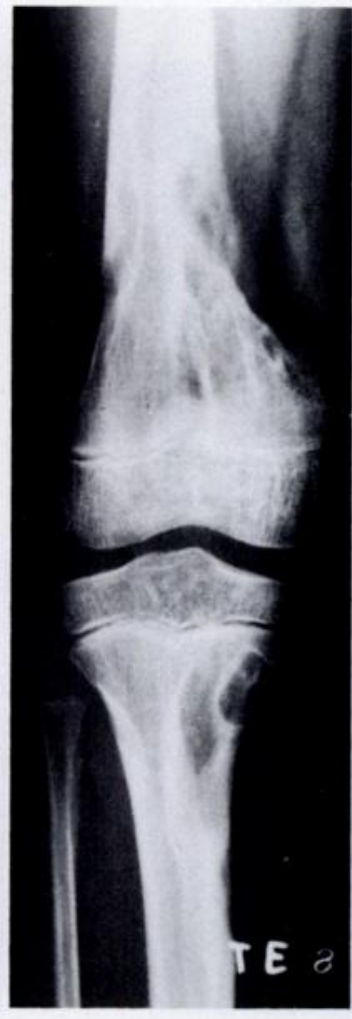

Fig. 6

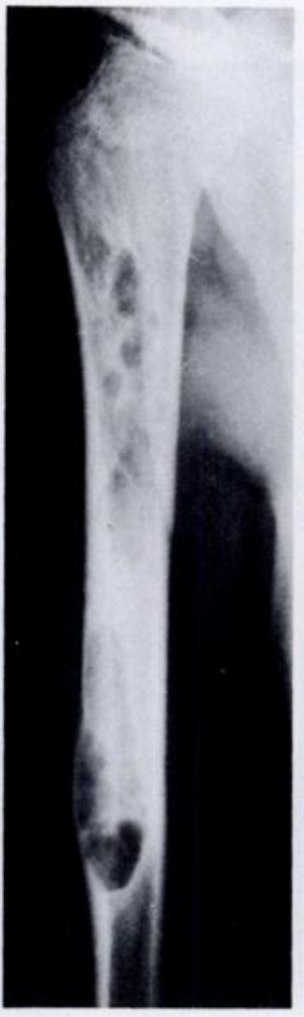

Fig. 7

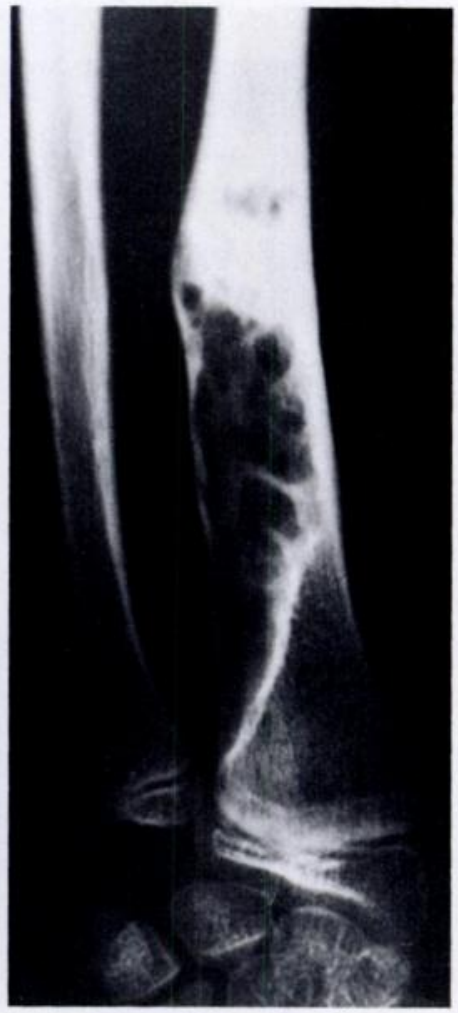

Fig. 8

Case 4. A 12-year-old boy with multiple non-ossifying fibromata affecting the right half of the body. Lesions are located in the iliac wing and upper femur (Fig. 5), and in the lower femur and upper tibia (Fig. 6). In the humerus the lesion extends from the proximal metaphysis to the distal third of the diaphysis (Fig. 7). The distal right radius is also involved (Fig. 8). 


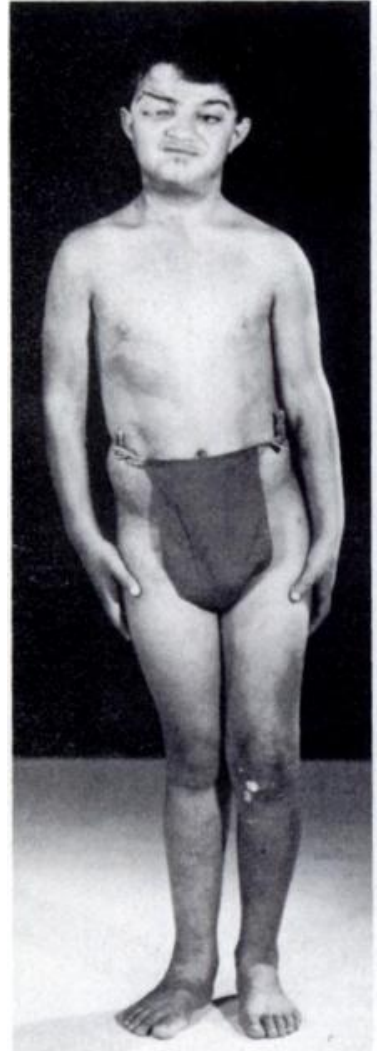

Fig. 9

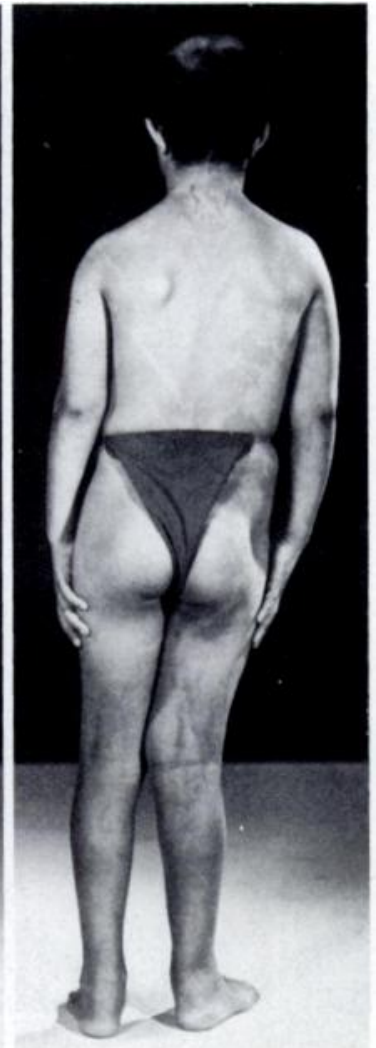

Fig. 10

Clinical photographs showing café-au-lait spots of the "coast of Maine" type on the right side of the body; alopecia; partial tarsorrhaphy of the right eye; valgus deformity of the right knee: and shortening of the right lower limb.

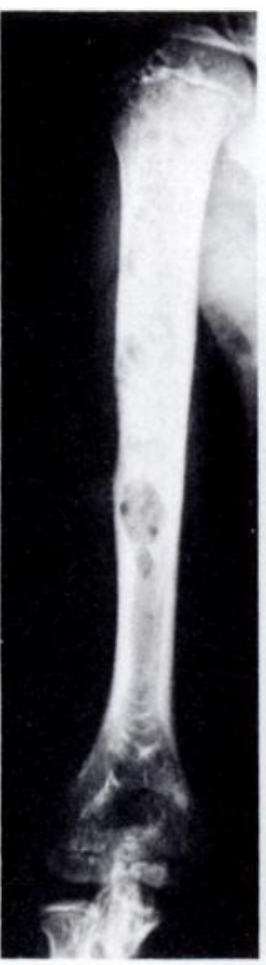

Fig. 11

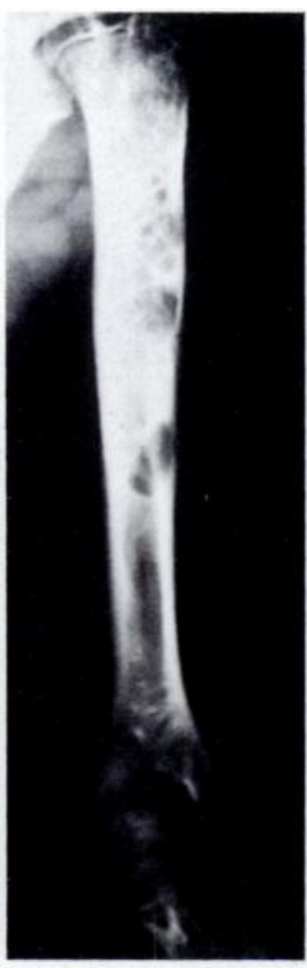

Fig. 12

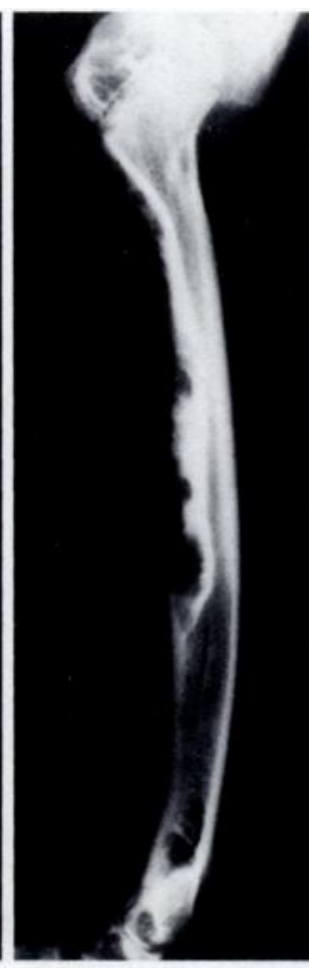

Fig. 13
Case 5 (Figs 9 to 25). An 11-year-old boy with multiple non-ossifying

\section{fibromata spreading all over the body.}

Case 5. This 11-year-old boy had no relevant family history. He presented with cafe-au-lait spots on the right side of the trunk, right arm and right leg (Figs 9 and 10), precocious puberty, mental retardation and alopecia. At the age of seven years he had sustained a pathological fracture of the right femur, which had healed with valgus deformity and two centimetres of shortening.

On examination of his eyes he was found to have bilateral conjunctival dermolipoma, right corneal leucoma and evidence of tarsorrhaphy of the lateral third of the eye. Examination of the fundus was possible only in the left eye which showed myopic degeneration, colobomata of the papilla, and pigmentary dispersion. The electroretinogram voltage was decreased bilaterally.

Radiographic examination of the entire skeleton showed multiple lucent areas in the metaphyses with extension into the diaphyses. The distribution of these lesions was bilateral and symmetrical, involving the humerus, radius, ilium, femur, tibia and fibula (Figs 11 to 25). Routine laboratory tests were normal. An osteotomy of the proximal tibia was performed on the right leg, and at the same operation an excision biopsy was done on the lesion in the distal femur. Ten years later it was found that the areas of osteolysis had undergone spontaneous regression with healing which was partial in some (Figs 16 to 19) and complete in others (Figs 22 to 25 ).

He sustained a second pathological fracture when he was 13 , and subsequently developed a varus deformity of the left knee.

The mental and ocular defects have remained unchanged, but no new clinical disorder has developed.

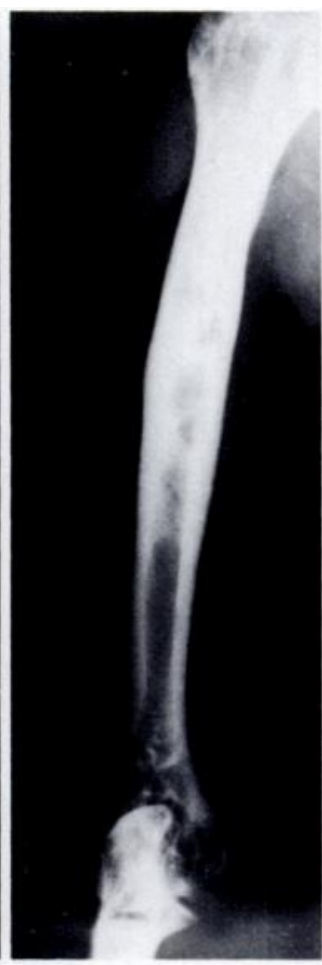

Fig. 14

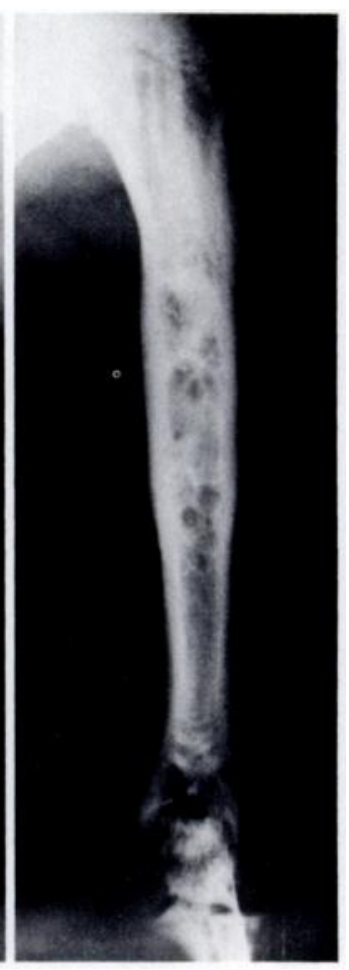

Fig. 15

Figures 11 and 12-Both humeri show widespread symmetrical osteolytic lesions, giving a loculated appearance. Figure 13-A lateral view shows that the lesion is intracortical, with a sharp margin and a sclerotic border, which causes narrowing of the medullary canal. Figures 14 and 15-Ten years later both humeri show partial healing of the lesions. 


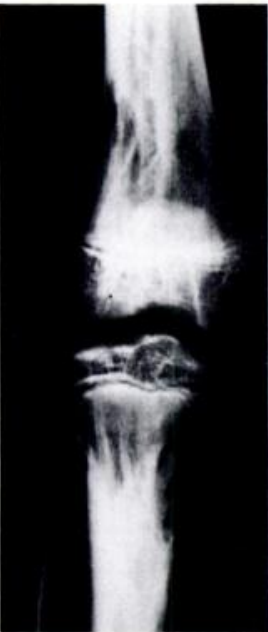

Fig. 16

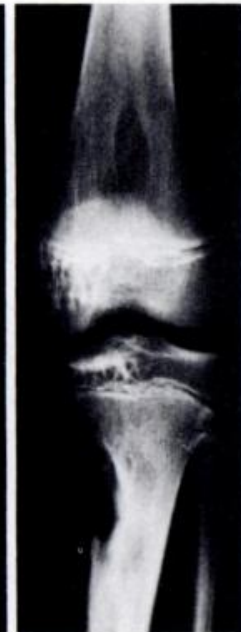

Fig. 17

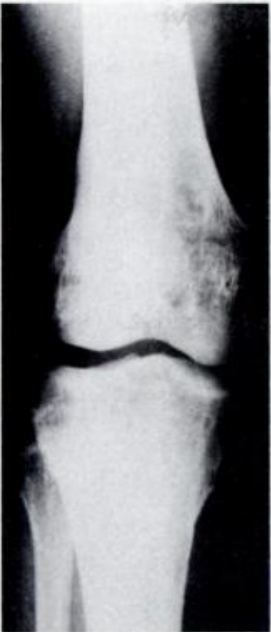

Fig. 18

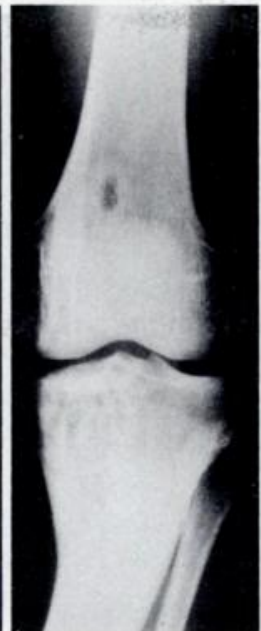

Fig. 19

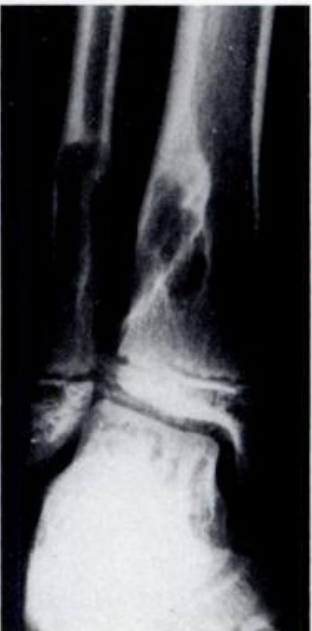

Fig. 20

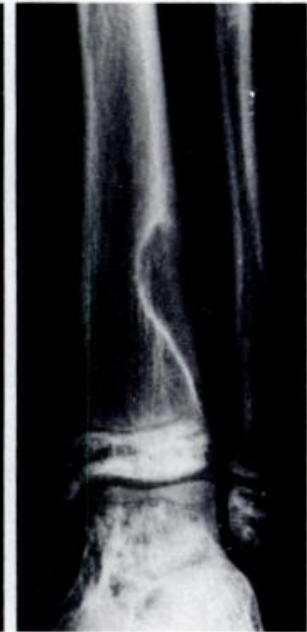

Fig. 21

Figures 16 and 17-Non-ossifying fibromata symmetrically located in both distal femora and in tibiae. Figures 18 and $19-$ Ten years later the lesions are almost completely healed. A valgus deformity of the right knee has been corrected by osteotomy. The varus deformity of the left knee resulted from a pathological fracture at 13 years of age. Figures 20 and $21-$ Bilateral involvement of both distal tibiae and fibulae.

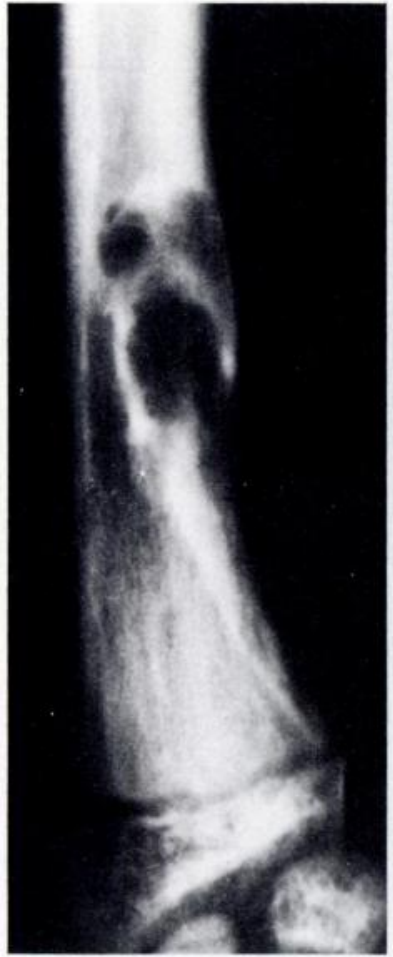

Fig. 22

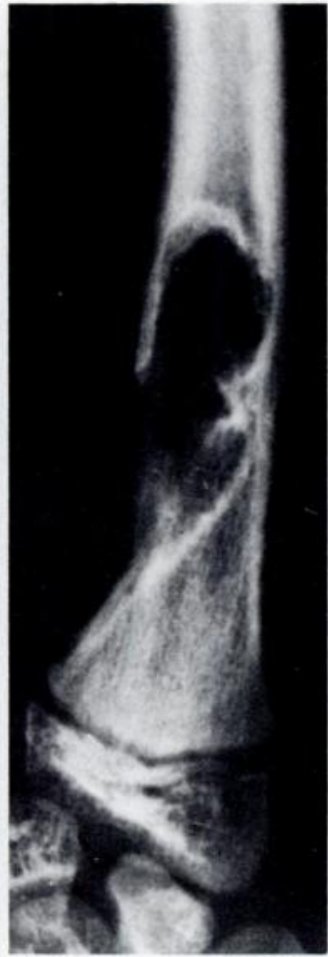

Fig. 23

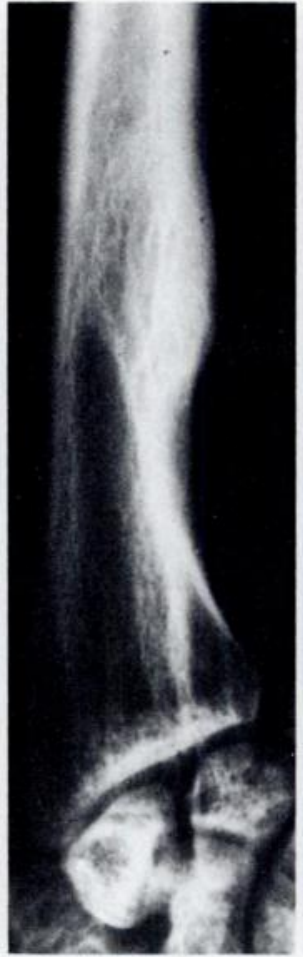

Fig. 24

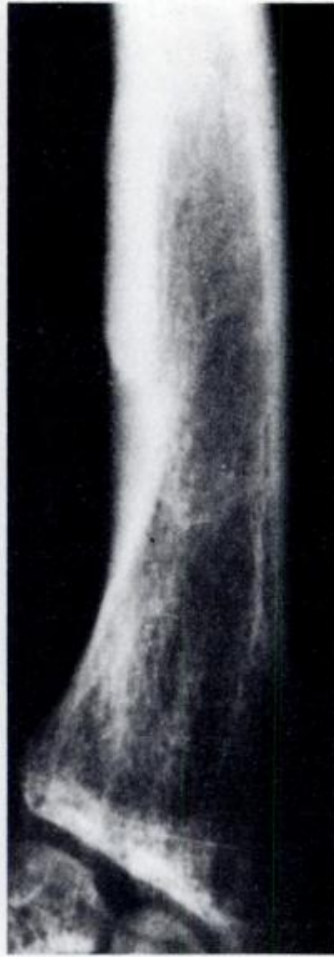

Fig. 25

Figures 22 and 23-Bilateral symmetrical non-ossifying fibromata of the distal radius. Figures 24 and $25-$ Ten years later both lesions have healed spontaneously and completely.

\section{DISCUSSION}

The radiographic picture and the extraskeletal anomalies seem to be characteristic features which all our cases have in common. The frequent association with cafe-aulait spots made us wonder if there might be some relationship with neurofibromatosis. In none of our patients, however, were neurofibromata observed, nor did any other clinical features of neurofibromatosis develop in those patients with a long-term follow-up Some of the anomalies observed in our cases have been described in association with neurofibromatosis: for example, precocious puberty, mental retardation and kyphoscoliosis (Holt 1978). The other anomalies, such as cryptorchidism, hypogonadism, ocular and cardiovascular defects are not associated with neurofibromatosis. In the literature there is only one report of multiple 
non-ossifying fibromata associated with manifest neurofibromatosis (Pitcock 1971). Holt (personal communication 1979) observed a case of multiple non-ossifying fibromata in a girl of 15 who also had neurofibromatosis, which was histologically proved by a biopsy from the scalp. Two cases of neurofibromatosis associated with multiple osteolytic lesions have been reported by Fellows, Bläker and Seifert (1971) and Klatte, Franken and Smith (1976). In the first case no exact diagnosis was established on biopsy, though the lesion consisted of fibroblasts. In the second case the bone biopsy was interpreted as "fibroxanthoma". In both cases the available data were compatible with a diagnosis of multiple non-ossifying fibromata associated with neurofibromatosis.

Some relationship between multiple non-ossifying fibromata and neurofibromatosis therefore seems possible, though the connection has not been firmly established. In the differential diagnosis of this syndrome polyostotic fibrous dysplasia should be considered, as it also may be associated with café-au-lait spots and precocious puberty. The radiographic picture of multiple non-ossifying fibromata is, however, different, and histologically the typical osseous component of fibrous dysplasia is lacking: moreover, the extraskeletal congenital anomalies seen in our syndrome are not observed in fibrous dysplasia.

In this syndrome the skeletal lesions tend to stop growing and to undergo spontaneous repair after skeletal maturation is complete, as with the solitary non-ossifying fibroma.

\section{REFERENCES}

Caffey J. On fibrous defects in cortical walls of growing tubular bones: their radiologic appearance, structure, prevalence, natural course and diagnostic significance. Adr Pediatr 1955:7:13-51.

Dahlin DC. Bone tumours : general aspects and data on 6221 cases. 3rd ed. Springfield, Illinois: CC Thomas, 1978;6-11.

Evans GA, Park WM. Familial multiple non-osteogenic fibromata. J Bone Joint Surg [Br] 1978;60-B:416-9.

Fellows KE, Bläker F, Seifert G. Mesodermale Dysplasie bei Neurofibromatose. Mschr Kinderheilk 1971; 119:592-9.

Holt JF. Neurofibromatosis in children. AJR 1978;130:615-39.

Jaffe HL. Non-ossifying fibroma. Tumors and tumorous conditions of the bones and joints. London: Henry Kimpton, 1958:83-91.

Klatte EC, Franken EA, Smith JA. The radiographic spectrum in neurofibromatosis. Semin Roentgenal 1976;11:17-33.

Mirra JM, Gold RH, Rand F. Disseminated nonossifying fibromas in association with café-au-lait spots (Jaffe-Campanacci syndrome). Clin Orthop 1982;168: 192-205.

Netherlands Committee on Bone Tumours. Non-ossifying fibroma. In: Seeger IW, trans. Radiological atlas of bone tumours. The Hague, Paris: Mouton, 1973:2:403-18.

Pitcock JA. Tumors and tumorlike lesions of bone. In:Crenshaw AH, ed. Campbell's operative orthopaedics. 5th ed. St Louis:CV Mosby, 1971: 1333-1411. 